Article

\title{
Control and Performance Evaluation of Multiphase FSPM Motor in Low-Speed Region for Hybrid Electric Vehicles
}

\section{Feng Yu ${ }^{1}$, Ming Cheng ${ }^{1, *}$, Kwok Tong Chau ${ }^{2}$ and Feng Li ${ }^{1}$}

1 School of Electrical Engineering, Southeast University, Nanjing 210096, China;

E-Mails: yufeng6575@sina.com (F.Y.); 1feng@ujs.edu.cn (F.L.)

2 Department of Electrical and Electronic Engineering, the University of Hong Kong, Hong Kong, China; E-Mail: ktchau@eee.hku.hk

* Author to whom correspondence should be addressed; E-Mail: mcheng@seu.edu.cn; Tel.: +86-25-8379-4152; Fax: +86-25-8379-1696.

Academic Editor: Joeri van Mierlo

Received: 29 July 2015 / Accepted: 10 September 2015 / Published: 21 September 2015

\begin{abstract}
The flux-switching permanent-magnet (FSPM) motor has been viewed as a highly reliable machine with both armature windings and magnets on the stator. Owing to the high torque-production capability with low torque ripple, FSPM motors with a higher number of phases are potential candidates for traction applications in hybrid electric vehicles (HEVs). However, existing research has mostly focused on the principles and static performance of multiphase FSPM motors, and little attention has been paid to advanced control strategies. In this paper, the fully decoupled current control of a 36/34-pole nine-phase FSPM (NP-FSPM) motor is developed and the performance under different operating conditions is investigated. The aim of the design is to alleviate cross coupling effects and unwanted low-order stator harmonic currents, to guarantee fast transient response and small steady-state error. In addition, its fault-tolerance is further elaborated. These features are very important in automotive applications where low torque pulsation, high fault-tolerant capability and high dynamic performance are of major importance. Firstly, the research status of multiphase FSPM motors is briefly reviewed. Secondly, the mathematical model in the $d q$ reference frames and control strategies are presented. Then, the control and performance of the NP-FSPM motor are evaluated by using MATLAB/Simulink. Finally, experiments on an NP-FSPM motor prototype are carried out to validate the study.
\end{abstract}


Keywords: FSPM; multiphase; hybrid electric vehicle; fully-decoupled; model; control

\section{Introduction}

Hybrid electric vehicles (HEVs) have attracted increasing attention owing to high demand for fuel-economy and environmentally friendly vehicles, which combine an internal combustion engine (ICE) and one or more electric motors [1-3]. Depending on the drivetrain, power sources are provided in various configurations to improve fuel consumption, emission, and performance.

In general, permanent magnet (PM) brushless machines are preferred for automation applications, where high torque and energy efficiency are the most valuable attributes [4,5]. Among these, flux switching permanent magnet (FSPM) motors are gaining interest as competitive candidates for the next generation of hybrid drivetrain application, because of their simple and rugged construction, sinusoidal back-electromotive force (EMF), easy thermal management, compact size and high torque capability [6,7]. To further promote the reliability and torque density of the motor drive, a nine-phase FSPM (NP-FSPM) motor drive has been proposed for hybrid electric vehicles recently $[8,9]$.

Multiphase FSPM motor is a promising form for reducing the amplitude of torque pulsation and increasing its frequency. Hence, four-, five-, six- and nine-phase FSPM motors have been successively studied in conjunction with different stator/rotor pole numbers in recent years. By employing increased winding redundancy compared to three phases, the stator winding of the multiphase FSPM motor can keep on forming the circular rotating magnetic field when a fault occurs in one or even more phases [10]. The static performance of FSPM motors with phase numbers ranging from four to six are investigated in [11], and it demonstrates that FSPM motors with high phase numbers offer significant benefits over three-phase topology in terms of torque density. In [12], design considerations for FSPM motors with five-phase 10/18-pole and 10/19-pole for high reliability applications were presented, showing that they inherently offer improved fault-tolerance and reduced PM material. In [8], three topologies of NP-FSPM for low-speed and fault-tolerant applications were developed, and a 36/34-pole NP-FSPM machine was chosen to achieve the negligible cogging torque. To prove the high fault-tolerance, two fault-tolerant control techniques, namely remedial brushless AC (BLAC) operation and remedial BLAC with harmonic current injection operation, are proposed for this machine [13]. As a result, multiphase FSPM motors can be regarded as one potential power source for HEV drive systems.

However, the current research on multiphase FSPM motors has mainly focused on the structure, operating principles, and static torque performance. The main current control technique presented for FSPM motors in the literature is hysteresis control [14,15], which provides a fast and simple solution for multiphase FSPM motor drives, but it uses variable switching frequency that results in unbalanced operation. In addition, the vector space decomposition (VSD) method in multiphase induction motors (IM) and PM synchronous motors (PMSM) is a known conventional method [16-18]. However, the operating principles and structure of FSPM motors are different from traditional IM and PMSM. For a multiphase FSPM motor, the PMs and armature windings are all located on the stator, while its rotor only consists of iron. Hence, the back-EMF and torque result from interaction between the motionless 
PM flux and rotor saliency, which differs from conventional multiphase PMSM [19]. Hence, control of a multiphase FSPM motor is more challenging because of the low-order stator harmonic currents arising from motor parameter inaccuracies and non-ideal behavior of the inverter.

Considering the points mentioned above, an NP-FSPM motor drive system for use in HEVs is developed. The main focus of this paper is to develop the mathematical model in the $d q$ reference frames and to implement fully decoupled current controls. Additionally, the controllability in post-fault operation is discussed. Both simulation and experiments are conducted to verify the low torque pulsation, high fault-tolerant capability and high dynamic performance of the drive system.

\section{Motor Features}

Figure 1 shows the arrangement of a 34-rotor-pole, 36-stator-pole winding distribution prototype for the NP-FSPM motor. There are four coils in each phase, e.g., four coils marked as "1" for phase 1, and each coil surrounding only one tooth. The adjacent phases are spatially displaced by $2 \pi / 9 \mathrm{rad}$. Thus, the resultant magneto-motive force (MMF) waveform will be established by nine equally spaced phase windings. The detailed specifications of the NP-FSPM motor are tabulated in Table 1.

The NP-FSPM motor can provide a maximum torque of $220 \mathrm{~N} \cdot \mathrm{m}$ with a top speed of $500 \mathrm{rpm}$, meeting the demands of low-speed high-torque applications. Nevertheless, the NP-FSPM motor also suffers from narrow constant power speed range as in the traditional PMSMs, due to the constant magnet flux provided by stator PMs.

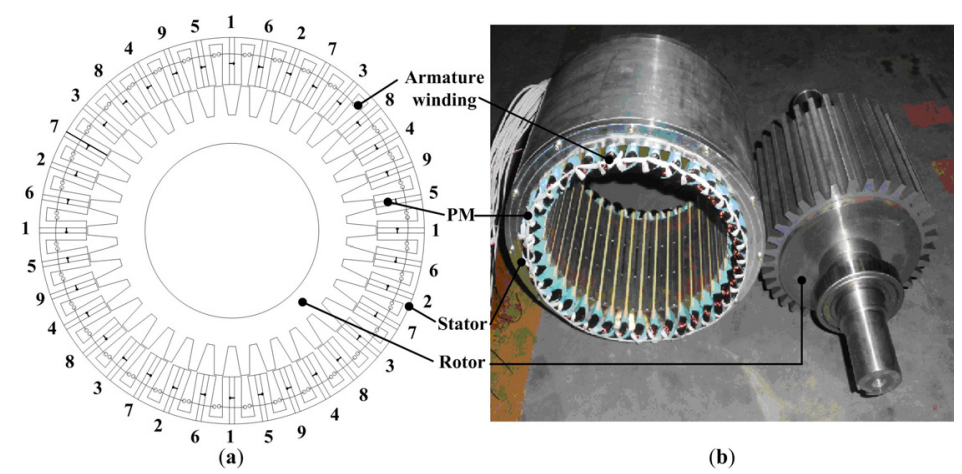

Figure 1. 36/34-pole NP-FSPM machine. (a) Cross section; (b) Prototype of stator and rotor.

Nonlinear transient finite-element (FE) analysis is utilized to calculate the back electromotive force (EMF) and the cogging torque of the machine.

Table 1. Key design parameters of the nine-phase flux-switching permanent-magnet (NP-FSPM) motor.

\begin{tabular}{cccc}
\hline Rated power & $10 \mathrm{~kW}$ & Rotor bore diameter & $120 \mathrm{~mm}$ \\
Rated speed & $500 \mathrm{rpm}$ & Air gap length & $1 \mathrm{~mm}$ \\
Rated phase voltage & $230 \mathrm{~V}$ & $B_{\mathrm{r}}$ of PMs & $1.2 \mathrm{~T}$ \\
Rated phase current & $4.83 \mathrm{~A}$ & Resistance per coil & $1.3 \Omega$ \\
Stack length & $155 \mathrm{~mm}$ & Stator-PM magnetic flux & $0.224 \mathrm{~Wb}$ \\
Stator inner diameter & $260 \mathrm{~mm}$ & Shaft length & $180 \mathrm{~mm}$ \\
Stator outer diameter & $327 \mathrm{~mm}$ & Rotary inertia & $0.05 \mathrm{~kg} \cdot \mathrm{m}^{2}$ \\
\hline
\end{tabular}


Figure $2 \mathrm{a}$ shows the back-EMF waveform of the machine at the rated speed of $500 \mathrm{rpm}$. As shown in the figure, the back-EMF waveform is sinusoidal. Thus, this kind of NP-FSPM motor can be driven as a brushless ac (BLAC) motor.

Unlike traditional PMSMs, the cogging torque of FSPM motors arises from the interaction between the stator-PMs and rotor slots where the stator winding is unexcited, which is shown in Figure $2 b$. It can be seen that the peak value of cogging torque is less than $0.5 \mathrm{~N} \cdot \mathrm{m}$, only $0.25 \%$ of the rated torque of the machine, due to the fact that the cogging torque decreases with increase in phase number and the frequency of the cogging torque increases with phase number and is proportional to the half of the stator pole number. Based on the FE analysis of the cogging torque, the low torque pulsation of the machine design is confirmed [20].

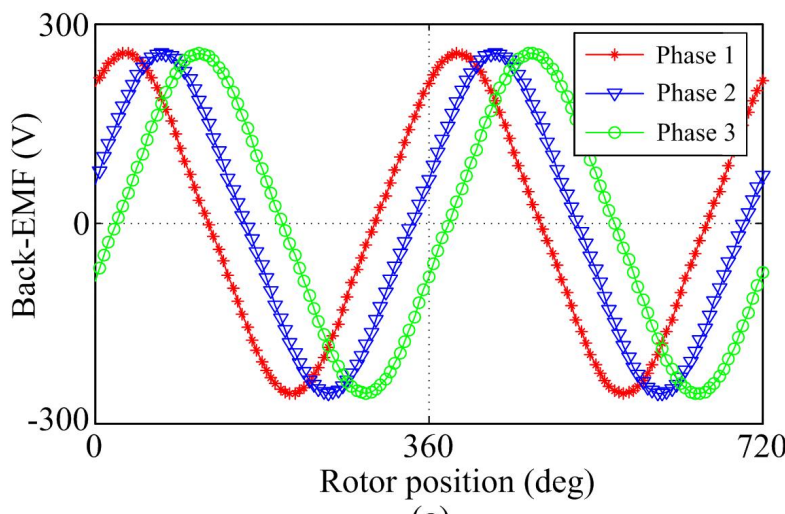

(a)

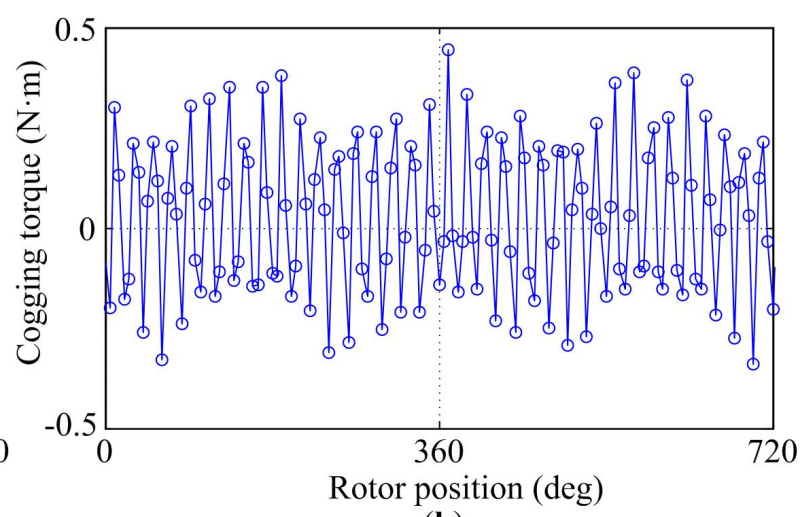

(b)

Figure 2. Static performance. (a) Back-EMF; (b) Cogging torque.

In some literature, the mutual inductance is ignored in the vector-controlled multiphase motor drive system, which could bring some defects to model accuracy in simulation. In this paper, the stator inductance profiles are also obtained from FE solutions of the NP-FSPM motor and stored in look-up tables of data that includes the rotor position dependence. Figure 3 shows the self- and mutual inductances in phase 1.

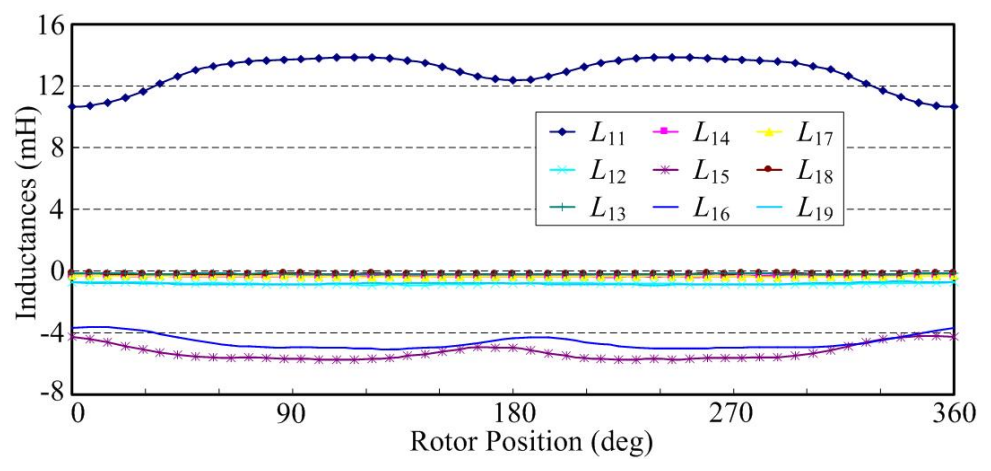

Figure 3. Self- and mutual inductances in phase 1.

\section{Mathematical Modeling Based on VSD}

To explore the control strategies for the NP-FSPM motor system, the machine mathematical model should adequately describe the dynamics of the drive system as simply as possible. In order to 
implement the VSD approach for a NP-FSPM motor, a minor modification should be firstly made in such a way that the $d$-axis is chosen to be the rotor position and where the stator-PM flux-linkage of phase 1 is the maximum. As a result, the following transformation matrices are adopted:

$$
\mathbf{T}(\theta)=\mathbf{C D}(\theta)
$$

$$
\mathbf{C}=\frac{2}{9}\left[\begin{array}{cccccccccc}
1 & \cos \gamma & \cos 2 \gamma & \cos 3 \gamma & \cos 4 \gamma & \cos 5 \gamma & \cos 6 \gamma & \cos 7 \gamma & \cos 8 \gamma \\
0 & \sin \gamma & \sin 2 \gamma & \sin 3 \gamma & \sin 4 \gamma & \sin 5 \gamma & \sin 6 \gamma & \sin 7 \gamma & \sin 8 \gamma \\
1 & \cos 3 \gamma & \cos 6 \gamma & \cos 9 \gamma & \cos 12 \gamma & \cos 15 \gamma & \cos 18 \gamma & \cos 21 \gamma & \cos 24 \gamma \\
0 & \sin 3 \gamma & \sin 6 \gamma & \sin 9 \gamma & \sin 12 \gamma & \sin 15 \gamma & \sin 18 \gamma & \sin 21 \gamma & \sin 24 \gamma \\
1 & \cos 5 \gamma & \cos 10 \gamma & \cos 15 \gamma & \cos 20 \gamma & \cos 25 \gamma & \cos 30 \gamma & \cos 35 \gamma & \cos 40 \gamma \\
0 & \sin 5 \gamma & \sin 10 \gamma & \sin 15 \gamma & \sin 20 \gamma & \sin 25 \gamma & \sin 30 \gamma & \sin 35 \gamma & \sin 40 \gamma \\
1 & \cos 7 \gamma & \cos 14 \gamma & \cos 21 \gamma & \cos 28 \gamma & \cos 35 \gamma & \cos 42 \gamma & \cos 49 \gamma & \cos 56 \gamma \\
0 & \sin 7 \gamma & \sin 14 \gamma & \sin 21 \gamma & \sin 28 \gamma & \sin 35 \gamma & \sin 42 \gamma & \sin 49 \gamma & \sin 56 \gamma
\end{array}\right] \mid \begin{aligned}
& \alpha_{1} \\
& \beta_{1} \\
& \alpha_{3} \\
& \beta_{3} \\
& \alpha_{5} \\
& \beta_{5} \\
& \alpha_{7} \\
& \beta_{7}
\end{aligned}
$$

$$
\mathbf{D}(\theta)=\left[\begin{array}{cccccccc}
\cos \theta & \sin \theta & 0 & 0 & 0 & 0 & 0 & 0 \\
-\sin \theta & \cos \theta & 0 & 0 & 0 & 0 & 0 & 0 \\
0 & 0 & \cos 3 \theta & \sin 3 \theta & 0 & 0 & 0 & 0 \\
0 & 0 & -\sin 3 \theta & \cos 3 \theta & 0 & 0 & 0 & 0 \\
0 & 0 & 0 & 0 & \cos 5 \theta & \sin 5 \theta & 0 & 0 \\
0 & 0 & 0 & 0 & -\sin 5 \theta & \cos 5 \theta & 0 & 0 \\
0 & 0 & 0 & 0 & 0 & 0 & \cos 7 \theta & \sin 7 \theta \\
0 & 0 & 0 & 0 & 0 & 0 & -\sin 7 \theta & \cos 7 \theta
\end{array}\right] \mid \begin{aligned}
& d_{1} \\
& q_{1} \\
& d_{3} \\
& q_{3} \\
& d_{5} \\
& q_{5} \\
& d_{7} \\
& q_{7}
\end{aligned}
$$

where $\gamma=2 \pi / 9$, and $\theta$ is the electrical rotor position. According to Kirchhoff's current law, zero sequence currents cannot flow into a symmetric star-connection winding, hence are neglected in this paper. The rotational transformation matrix Equation (1) consists of the stationary frame transformation matrix $\boldsymbol{C}$ and rotation matrix $\boldsymbol{D}(\theta)$.

According to the VSD theory for the NP-FSPM motor, through Equation (1), the phase-variable (current, voltage or flux linkage) are decoupled into four separate synchronous reference frames, which are called $d_{1-q_{1}}$ plane and $d_{\mathrm{h}}-q_{\mathrm{h}}(h=3,5,7)$ plane in this paper, yielding a simple solution to the description of the machine model.

In a perfectly symmetrical situation, with the rotational transformation matrix Equation (1), the fundamental component and the harmonics of the order of $18 k \pm 1(k=0,1,2,3 \ldots)$ are mapped into the $d_{1-q_{1}}$ plane, the harmonics of the order of $18 k \pm 3$ are mapped into the $d_{3}-q_{3}$ plane, the order of $18 k \pm 5$ are mapped into the $d_{5-}-q_{5}$ plane, and the order of $18 k \pm 7$ are mapped into $d_{7-q 7}$ plane. Those harmonic components mapped in the $d_{1}-q_{1}$ plane contribute to the electromechanical energy conversion, while $d_{\mathrm{h}-q_{\mathrm{h}}}(h=3,5,7)$ plane components do not generate electrical torque. As discussed in [14], any imbalance in the stator windings or supply voltages causes the fundamental components and all the harmonics to appear in each reference frame in the multiphase induction motor, which also occurs in the multiphase FSPM motors. To verify the effectiveness of the controllability of harmonic components in the nine-phase system, the low-order harmonics, such as the third-, fifth-, and seventhharmonic components, are considered in this paper, accompanied with the fundamental component.

Based on Equation (1), the stator voltage equations in the $d_{1}-q_{1}$ and $d_{\mathrm{h}}-q_{\mathrm{h}}$ reference frames are:

$$
\left\{\begin{array}{l}
u_{d 1}=R_{s} i_{d 1}+L_{d 1} d i_{d 1} / d t-\omega L_{q 1} i_{q 1} \\
u_{q 1}=R_{s} i_{q 1}+L_{q 1} d i_{q 1} / d t+\omega\left(L_{d 1} i_{d 1}+\psi_{m}\right) \\
u_{d h}=R_{s} i_{d h}+L_{d h} d i_{d h} / d t-h \omega L_{q h} i_{q h} \\
u_{q h}=R_{s} i_{d h}+L_{q h} d i_{d h} / d t+h \omega L_{d h} i_{q h}
\end{array}\right.
$$


where $L_{\mathrm{d} 1}$ and $L_{\mathrm{q} 1}$ are stator inductance in $d_{1}$-axis and $q_{1}$-axis respectively, $L_{\mathrm{dh}}$ and $L_{\mathrm{q}}$ are stator inductance in $d_{\mathrm{h}}-q_{\mathrm{h}}$ axis, $R_{\mathrm{s}}$ is the phase resistance, $\omega$ is the rotor electrical angular velocity, and $\psi_{\mathrm{m}}$ is the flux linkage established by stator-PMs.

The electromagnetic torque can be derived from partial derivative of co-energy with respect to mechanical rotor position as:

$$
T_{e}=\frac{9}{2} p\left[\psi_{m} i_{q 1}+\sum_{h=1,3,5,7} h\left(L_{d h}-L_{q h}\right) i_{d h} i_{q h}\right]
$$

where $p$ is the number of pole-pairs. The electromagnetic torque is composed of two parts. The first part is the PM torque, which arises from the interaction of the stator-PM flux and $q 1$-axis stator current component. The second part is the reluctance-torque component caused by inductance variation as a function of the rotor position.

\section{Control Strategies of NP-FSPM Motor}

\subsection{Torque-Speed Characteristic Analysis}

As to traction of HEVs electric propulsion, high/smooth torque output in the low speed region and a wide speed range in the constant-power region are preferable, to achieve fast torque response and high-speed cruise performance [2]. Therefore, multiphase FSPM motors used in HEVs need to exert a constant torque (CT) mode over the low-speed region and operate with field-weakening (FW) mode in the high speed region. The typical torque-speed characteristic is given by Figure 4 [3].

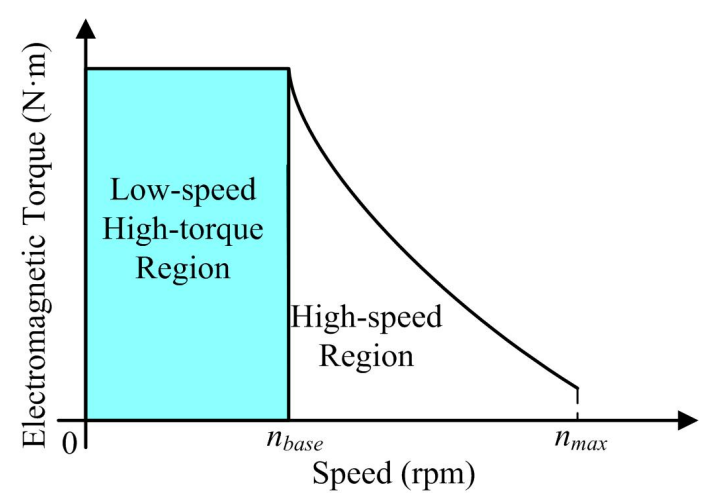

Figure 4. Torque-speed characteristic of NP-FSPM.

This paper mainly focuses on the control and performance of the NP-FSPM motor in the low-speed region.

\subsection{Fully-Decoupled Current Control during Normal Operation}

In normal operations, the electric propulsion should perform with low torque pulsation and fast dynamic response. The majority of challenges in the NP-FSPM machine are related to the issues with currents applied to the motor. According to Section 3, if VSD is applied to phase currents, the $d_{1}-q_{1}$ and $d_{\mathrm{h}}-q_{\mathrm{h}}$ plane currents are directly controlled variables in the stator-flux-oriented scheme and consequently can be effectively manipulated. This feature provides a very effective way to solve 
current-related issues and strongly supports stator-flux-oriented control as the recommended control method for the NP-FSPM machine.

The control scheme is based on a conventional solution of synchronous current control using typical linear proportional and integral (PI) controllers. Figure 5 presents the block diagram of the fully-decoupled control scheme. Four pairs of synchronous current controllers in conjunction with eight PIs are used to regulate both the $d_{1}-q_{1}$ plane currents and the $d_{\mathrm{h}}-q_{\mathrm{h}}(h=3,5,7)$ plane currents. Since $d_{\mathrm{h}}-q_{\mathrm{h}}$ is also a synchronous frame, any specific low-order harmonic (such as the third, the fifth and the seventh) currents which would appear as dc components of the $d_{\mathrm{h}}-q_{\mathrm{h}}$ current controller through transformation $\boldsymbol{T}(\theta)$ will be completely controlled. Consequently, to eliminate the unwanted low-order harmonic currents, the reference currents in the $d_{\mathrm{h}}-q_{\mathrm{h}}$ plane should always be:

$$
i_{d h}^{*}=i_{q h}^{*}=0
$$

where "*" denotes the reference value.

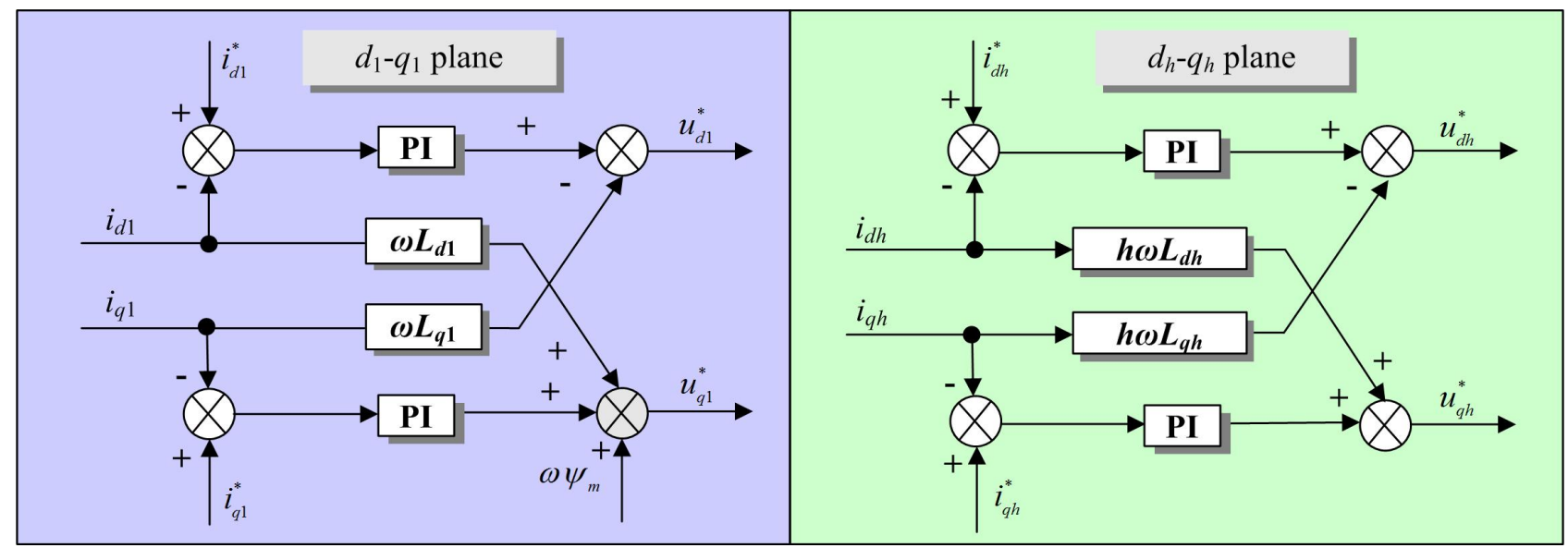

Figure 5. Fully-decoupled current control scheme.

In order to improve the dynamic performance in terms of PI controller based current control, the cross coupling effects between synchronous voltages should be cancelled out by feeding the following positive compensation:

$$
\left\{\begin{array}{l}
u_{d 1}^{\text {decoupled }}=-\omega L_{q 1} i_{q 1} \\
u_{q 1}^{\text {decoupled }}=\omega L_{d 1} i_{d 1}+\omega \psi_{m}
\end{array},\left\{\begin{array}{l}
u_{d h}^{\text {decoupled }}=-h \omega L_{q h} i_{q h} \\
u_{q h}^{\text {decoupled }}=h \omega L_{d h} i_{d h}
\end{array}\right.\right.
$$

On the basis of the mathematical model of the NP-FSPM motor, the decoupling system in the $d_{1}-q_{1}$ and $d_{\mathrm{h}}-q_{\mathrm{h}}$ planes has the following simple transfer functions:

$$
\left\{\begin{array}{l}
\frac{I_{d 1}(s)}{U_{d 1}(s)}=\frac{1}{R_{s}+L_{d 1} s},\left\{\begin{array}{l}
\frac{I_{d h}(s)}{U_{d h}(s)}=\frac{1}{R_{s}+L_{d h} s} \\
\frac{I_{q 1}(s)}{U_{q 1}(s)}=\frac{1}{R_{s}+L_{q 1} s}
\end{array},\left\{\begin{array}{l}
\frac{1}{I_{q h}(s)} \\
U_{q h}(s)
\end{array} \frac{1}{R_{s}+L_{q h} s}\right.\right.
\end{array}\right.
$$

Due to the controllability of $d_{\mathrm{h}}-q_{\mathrm{h}}$ plane currents, robust control voltage generation can be achieved in terms of Equations (7) and (8), even in the condition of low-order harmonic currents caused by motor parameter inaccuracies or nonlinear characteristics of the voltage source inverter (VSI). Hence, 
the significance of the accuracy of the NP-FSPM motor parameters in the fully-decoupled current control scheme appears not to be a major problem.

\subsection{Reconstruction of Harmonic Current Components during Post-Fault Operation}

Moreover, the electric propulsion should also exhibit high fault tolerance in the event of a fault condition. As the stator $d_{1}-q_{1}$ current components are required for the flux/torque control in the NP-FSPM motor, another three pairs of stator harmonic current components (the third, the fifth and the seventh), regarded as additional degree of freedom (ADF), can be effectively utilized for an appropriate post-fault operating strategy. It should be noted that the ADFs have been used to deal with open-circuit fault in multiphase machines for various specific aims, such as minimum loss or maximum torque output [21-23]. However, there is no evidence that fault-tolerant controllability has ever been attempted before by dispensing with these additional degrees of freedom. Hence, possibilities for the implementation of a fault-tolerant operating strategy will be further elaborated.

In order to maintain the torque-producing current components $i_{\alpha 1}$ and $i_{\beta 1}$ during post-fault operation, namely, to keep the undisturbed MMF, for the case with open-circuit fault in phase 1, the following constrained optimization problem must be solved [13]:

$$
\begin{gathered}
\text { Minimize: } i_{1 \alpha}^{2}+i_{1 \beta}^{2}+i_{3 \alpha}^{2}+i_{3 \beta}^{2}+i_{5 \alpha}^{2}+i_{5 \beta}^{2}+i_{7 \alpha}^{2}+i_{7 \beta}^{2} \\
\text { Subject to: } 1 \times i_{1 \alpha}+0 \times i_{1 \beta}+1 \times i_{3 \alpha}+0 \times i_{3 \beta}+1 \times i_{5 \alpha}+0 \times i_{5 \beta}+1 \times i_{7 \alpha}+0 \times i_{7 \beta}=0
\end{gathered}
$$

Based on the solution of stationary frame current components with minimum loss criteria Equation (9), implementation of a fault-tolerant control strategy can be further achieved in terms of seven kinds of harmonic current components reconstruction modes, which are listed in Table 2, where Minor Reconstruction, Mid Reconstruction and Max Reconstruction, represent the amount of modification in the current controller. Taking the first Minor Reconstruction mode as an example, only the third harmonic current component $i_{\alpha 3}$ is reconstructed to be $-i_{\alpha 1}$ while the other harmonic current components are still kept to be zero.

\begin{tabular}{|c|c|c|}
\hline Minor Reconstruction & Mid Reconstruction & Max Reconstruction \\
\hline$i_{\alpha 3}=-i_{\alpha 1}$ & $i_{\alpha 3}=i_{\alpha 5}=-i_{\alpha 1} / 2$ & \\
\hline$\left(i_{\beta 3}=i_{\alpha 5}=i_{\beta 5}=i_{\alpha 7}=i_{\beta 7}=0\right)$ & $\left(i_{\beta 3}=i_{\beta 5}=i_{\alpha 7}=i_{\beta 7}=0\right)$ & \\
\hline or & or & \\
\hline$i_{a 5}=-i_{a 1}$ & $i_{\alpha 3}=i_{\alpha 7}=-i_{\alpha 1} / 2$ & $i_{\alpha 3}=i_{\alpha 5}=i_{\alpha 7}=-i_{\alpha 1} / 3$ \\
\hline$\left(i_{\alpha 3}=i_{\beta 3}=i_{\beta 5}=i_{\alpha 7}=i_{\beta 7}=0\right)$ & $\left(i_{\beta 3}=i_{\alpha 5}=i_{\beta 5}=i_{\beta 7}=0\right)$ & $\left(i_{\beta 3}=i_{\beta 5}=i_{\beta 7}=0\right)$ \\
\hline or & or & \\
\hline$i_{\alpha, 7}=-i_{\alpha 1}$ & $i_{\alpha 5}=i_{\alpha 7}=-i_{\alpha 1} / 2$ & \\
\hline$\left(i_{\alpha 3}=i_{\beta 3}=i_{\alpha 5}=i_{\beta 5}=i_{\beta 7}=0\right)$ & $\left(i_{\alpha 3}=i_{\beta 3}=i_{\beta 5}=i_{\beta 7}=0\right)$ & \\
\hline
\end{tabular}

Table 2. Post-fault operation modes.

\subsection{Carrier-Based Modulator}

A well-defined switch frequency characteristic performed in the electric propulsion is also preferred. On the other hand, current harmonics caused by non-sinusoidal air gap flux can be reduced by 
intentionally feeding the right combination of supply harmonic voltages to the machine. In order to produce independent voltage vector in each $d-q$ plane and ease the real-time implementation, an equivalent space vector pulse-width-modulation (SVPWM) modulator using max-min injection is adopted here.

First, by applying inverse $\boldsymbol{T}(\theta)$, the reference phase voltage phasor $\boldsymbol{U}_{\mathrm{p}}$ is formed as:

$$
\mathbf{U}_{p}=\mathbf{T}^{-1}(\theta) \mathbf{U}_{d q}
$$

where $\boldsymbol{U}_{\mathrm{p}}=\left[u_{1}, u_{2}, u_{3}, u_{4}, u_{5}, u_{6}, u_{7}, u_{8}, u_{9}\right]^{\mathrm{T}}, \boldsymbol{U}_{\mathrm{dq}}=\left[u_{\mathrm{d} 1}, u_{\mathrm{q} 1}, u_{\mathrm{d} 3}, u_{\mathrm{q} 3}, u_{\mathrm{d} 5}, u_{\mathrm{q} 5}, u_{\mathrm{d} 7}, u_{\mathrm{q} 7}\right]^{\mathrm{T}}$.

Then, phase voltage references with max-min injection are compared with a high-frequency carrier waveform (usually a triangular signal). The modulated signal can be given as:

$$
\mathbf{U}_{m}=\mathbf{U}_{p}+U_{z}
$$

where $U_{z}$ represents the zero-sequence signal, which can be obtained as:

$$
U_{z}=-\frac{1}{2}\left[\max \left\{\mathbf{U}_{p}\right\}+\min \left\{\mathbf{U}_{p}\right\}\right]
$$

Due to the similar modulation pattern used with conventional SVPWM, the same performances are achieved with max-min injection, in terms of total harmonic distortion (THD), maximum voltage, etc. [24]. With regard to the design constraints, input voltages are limited by the inverter dc-link voltage $V_{\mathrm{dc}}$, which induces a hexagonal voltage boundary rotating in the $d_{1}-q_{1}$ voltage plane with angular speed $\omega$. For the sake of simplicity, the boundary can be approximated by the circle with radius $V_{\mathrm{dc}} / 1.58$, inscribed in the hexagon.

\subsection{Closed-Loop Speed Control}

On the basis of a fully-decoupled current controller built as inner loop, the closed-loop speed control constructed as outer loop is relatively straightforward in control of the motor to supply the required amount of torque to the load at a given speed. In addition, the torque in an NP-FSPM motor is a function of $q_{1}$-axis current and stator-PM flux according to Equation (5). Hence, a PI regulator based speed control is directly employed to determine the error between reference speed and actual speed, and generates the torque-producing $q_{1}$-axis reference current $i_{\mathrm{q} 1}{ }^{*}$.

Figure 6 shows the block diagram of the closed-loop speed operation of the NP-FSPM motor. It is a cascade structure made up of one speed controller and four pairs of $d$ - $q$ plane current controllers. Furthermore, a software switch is utilized in the controller to select and activate healthy or post-fault operation. 


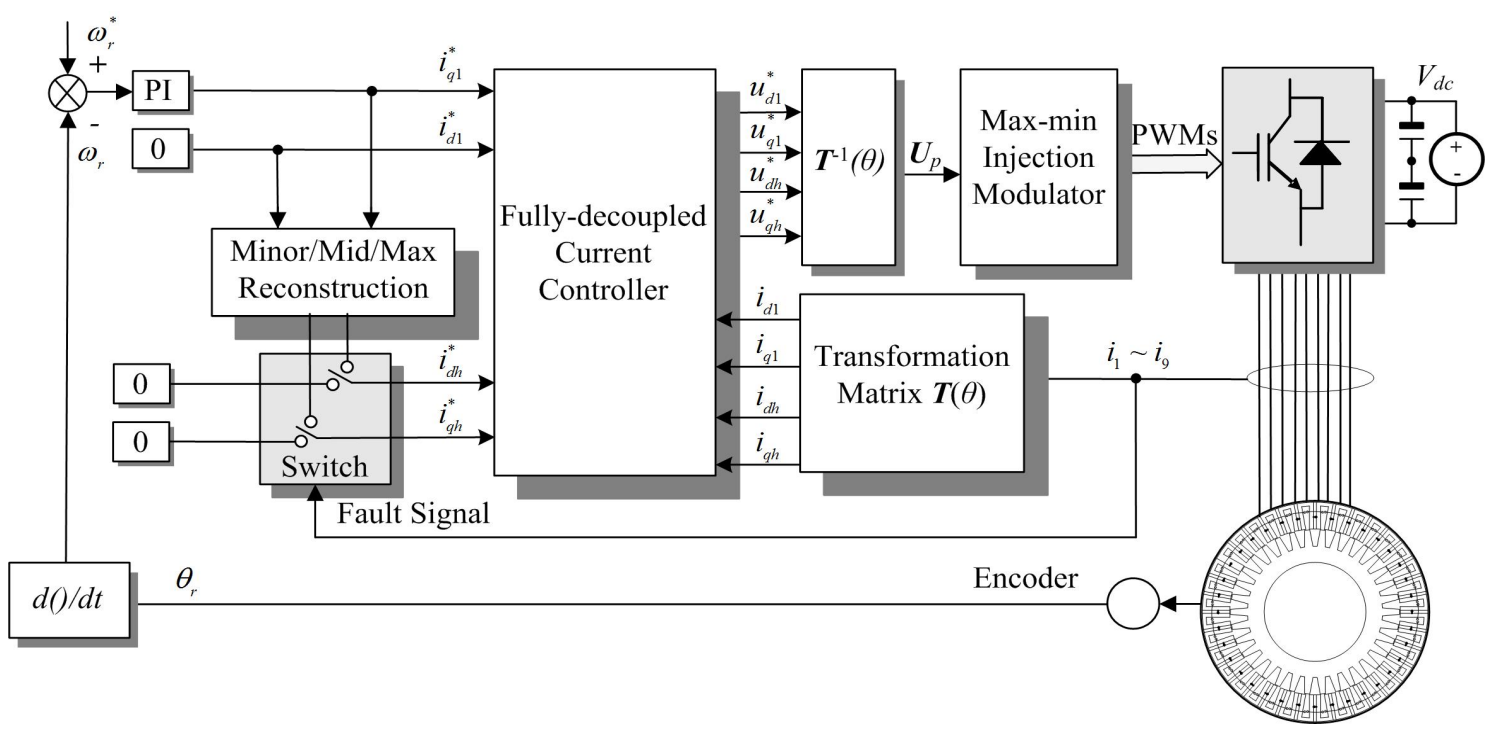

Figure 6. Closed-loop speed control of NP-FSPM motor for HEV.

\section{Simulation and Performance Analysis}

The simulations were conducted to evaluate the control and performance of the NP-FSPM motor drive. Due to the nature of the machine, the machine parameters vary significantly with load and position. In order to have a realistic representation of the machine, finite-element analysis was used to determine the PM flux linkage, self-inductances and mutual inductances as a function of position and load. As a result, a physical phase variable model built in the MATLAB/Simulink environment was adopted. The phase voltage and electromagnetic torque equations describing the NP-FSPM machine can then be written as:

$$
\begin{aligned}
& \mathbf{U}_{p}=\mathbf{R} \mathbf{I}_{s}+\mathbf{L}(\theta) \frac{d \mathbf{I}_{s}}{d t}+\omega \frac{\partial \mathbf{L}(\theta)}{\partial \theta} \mathbf{I}_{s}+\mathbf{E} \\
& T_{e}=p\left(\frac{1}{2} \mathbf{I}_{s}^{T} \frac{\partial \mathbf{L}(\theta)}{\partial \theta} \mathbf{I}_{s}+\mathbf{I}_{s}^{T} \frac{\mathbf{E}}{\omega}\right)+T_{c}(\theta)
\end{aligned}
$$

where $\boldsymbol{I}_{\mathrm{s}}=\left[i_{1}, i_{2}, \ldots, i_{8}, i_{9}\right]^{\mathrm{T}}$ is phase current phasor, $\boldsymbol{R}=\operatorname{diag}\left(R_{\mathrm{s}}, R_{\mathrm{s}}, \ldots, R_{\mathrm{s}}, R_{\mathrm{s}}\right)$ is the phase resistance matrix, $\boldsymbol{E}=\left[e_{1}, e_{2}, \ldots, e_{8}, e_{9}\right]^{\mathrm{T}}$ is back-EMF phasor, $\boldsymbol{L}(\theta)$ is the stator inductance matrix, $T_{\mathrm{c}}(\theta)$ is cogging torque. The preferred inductance parameters are identified from $d_{\mathrm{h}}$ and $q_{\mathrm{h}}$ - axis step responses as listed in Table 3.

Table 3. Inductance parameters.

\begin{tabular}{cccc}
\hline $\boldsymbol{d}_{\mathbf{1}}-\boldsymbol{q}_{\mathbf{1}}$ Plane & $\boldsymbol{d}_{\mathbf{3}}-\boldsymbol{q}_{\mathbf{3}}$ Plane & $\boldsymbol{d}_{\mathbf{5}}-\boldsymbol{q}_{\mathbf{5}}$ Plane & $\boldsymbol{d}_{\mathbf{7}}-\boldsymbol{q}_{\mathbf{7}}$ Plane \\
\hline$i_{\mathrm{d} 1}=16.6 \mathrm{mH}$ & $i_{\mathrm{d} 3}=14.9 \mathrm{mH}$ & $i_{\mathrm{d} 5}=10.5 \mathrm{mH}$ & $i_{\mathrm{d} 7}=4.1 \mathrm{mH}$ \\
$i_{\mathrm{q} 1}=18.3 \mathrm{mH}$ & $i_{\mathrm{q} 3}=14.7 \mathrm{mH}$ & $i_{\mathrm{q} 5}=9.7 \mathrm{mH}$ & $i_{\mathrm{q} 7}=4.2 \mathrm{mH}$ \\
\hline
\end{tabular}

Firstly, the fully-decoupled current control is applied and tested to evaluate the steady-state performance of the NP-FSPM motor drive. The proportional coefficients of PIs have been chosen in order to obtain a crossover frequency with a safety margin to dead-time, and the integral coefficients of PIs have been chosen in order to get critical damping behavior. The key parameters of those PIs are 
shown in Table 4. An outer speed control loop (PI controller) is then added to the control scheme $\left(K p \_s p e e d=0.35\right.$, and $K i$ speed $\left.=16\right)$ to evaluate the dynamic performance and reliability. The PWM switching frequency is set to $10 \mathrm{kHz}$.

Table 4. Key parameters for inner proportional and integral (PIs).

\begin{tabular}{|c|c|c|c|}
\hline$d_{1}-q_{1}$ Plane & $d_{3^{-}-q_{3} \text { Plane }}$ & $d_{5}-q_{5}$ Plane & $d_{7}-q_{7}$ Plane \\
\hline$K p \_d_{1}=320$ & $K p \_d_{3}=250$ & $K p \_d_{5}=50$ & $K p \_d_{7}=150$ \\
\hline$K i \_d_{1}=20$ & $K i \_d_{3}=20$ & $K i \_d_{5}=20$ & $K i d_{7}=20$ \\
\hline$K p \_q_{1}=320$ & $K p \_q_{3}=250$ & $K p \_q_{5}=50$ & $K p \_q_{7}=150$ \\
\hline$K i d_{1}=20$ & $K i d_{3}=20$ & $K i d_{5}=20$ & $K i d_{7}=20$ \\
\hline
\end{tabular}

\subsection{Steady-State Performance}

In this simulation, the driver works in constant current control mode without or with closed-loop harmonic current controller, the $i_{\mathrm{q} 1}$ reference is $2.7 \mathrm{~A}$. Figure $7 \mathrm{a}$ shows the case where current control in the $d_{\mathrm{h}}-q_{\mathrm{h}}(h=3,5,7)$ plane is omitted. It can be seen that phase current contains rich current harmonics because of the inability of the control to compensate the effect of the non-sinusoidal air-gap flux. As a comparison, Figure $7 \mathrm{~b}$ shows the case where fully decoupled current controls are operating as developed in this paper. A major reduction can be seen in the magnitude of the harmonic currents (second harmonic reduces 10\% and third 20\%), as shown in the FFT result. In addition, the steady-state current errors in the $d_{\mathrm{h}}-q_{\mathrm{h}}$ plane are effectively eliminated when the fully decoupled current control is activated and the $d_{3}$-axis and $q_{3}$-axis current waveforms are given in Figure $7 \mathrm{c}$. The results indicate that the fully decoupled current control manages to suppress the low-order harmonics in the NP-FSPM motor, hence ensuring sinusoidal phase currents.
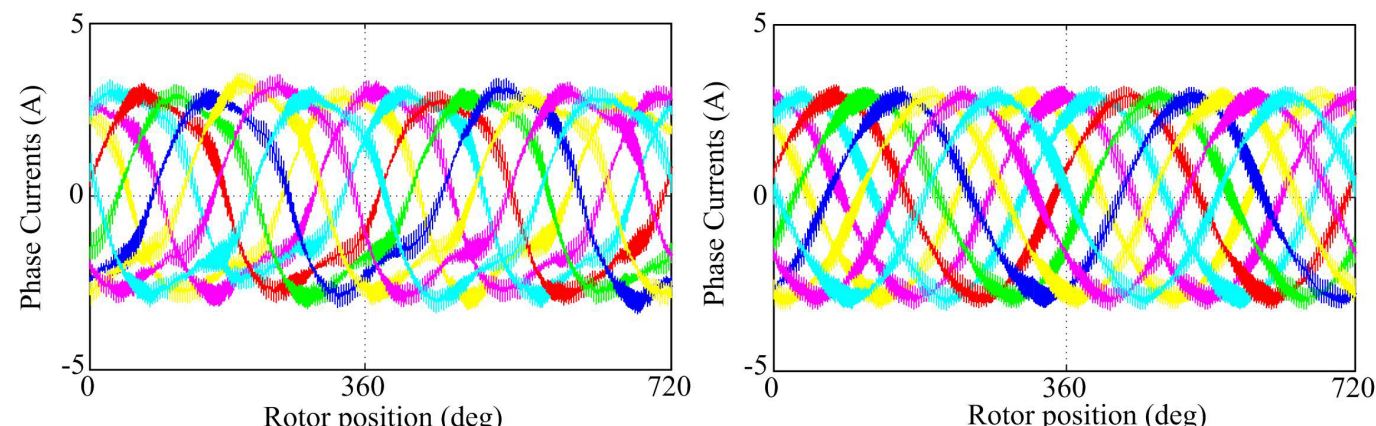

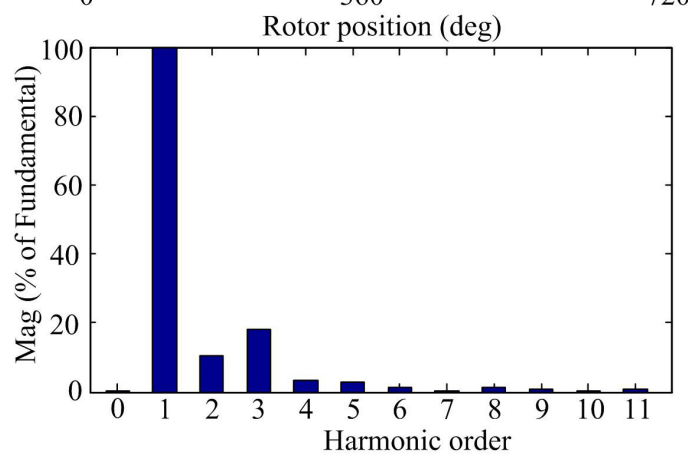

(a)

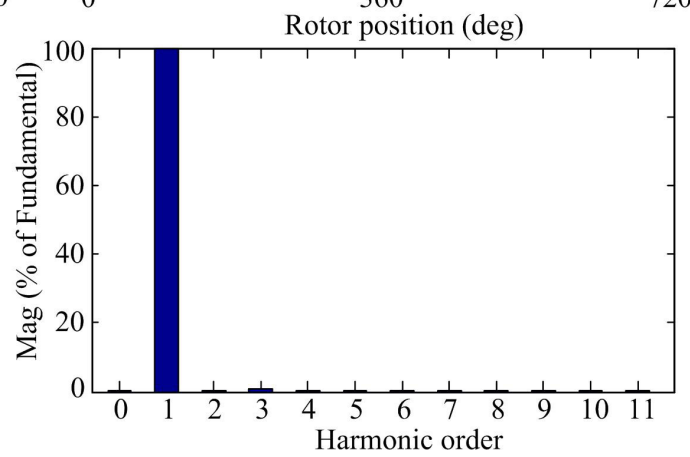

(b)

Figure 7. Cont. 


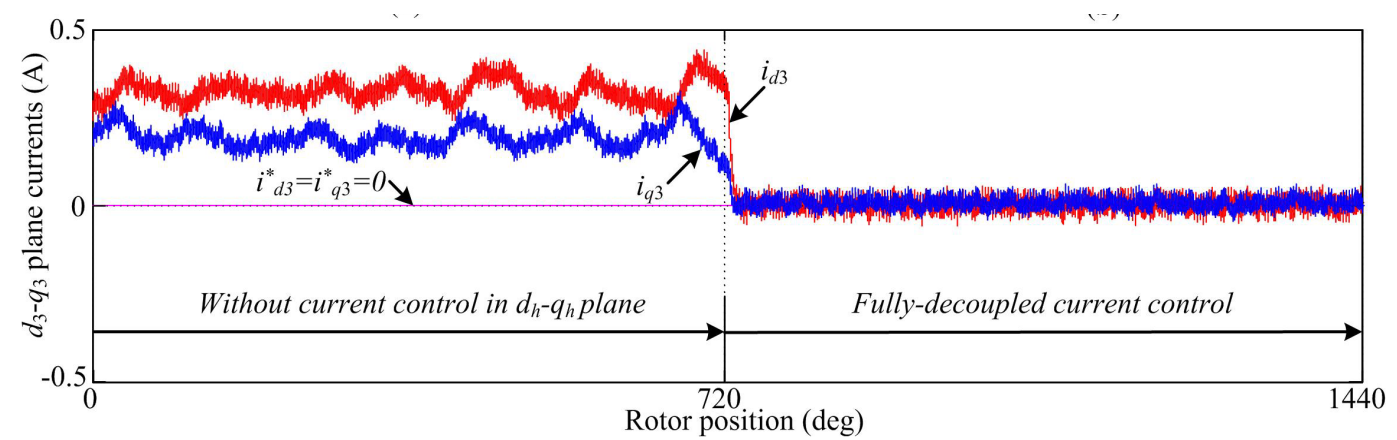

(c)

Figure 7. Simulation evaluation of steady-state performance. (a) Without current control in the $d_{\mathrm{h}}-q_{\mathrm{h}}$ plane; (b) Fully-decoupled current control; (c) Steady-state current errors in $d_{3}-q_{3}$ plane.

In reality, some key motor parameters, such as stator resistance and mutual inductance, may change during different working states influenced by temperature and magnetic saturation. To verify the sensitivity of the control system to motor parameters, $5 \Omega$ resistances are added between the machine and the VSI of the phases 1 and 2 during the period from 720-2160 deg. For simplicity, the controllers without current control in $d_{\mathrm{h}}-q_{\mathrm{h}}$ plane and with fully-decoupled current control are referred to Mode-I and Mode-II, respectively. Figure 8 presents the currents of phases 1,2 and 3, showing that even severe imbalance can be eliminated with fully-decoupled current control.

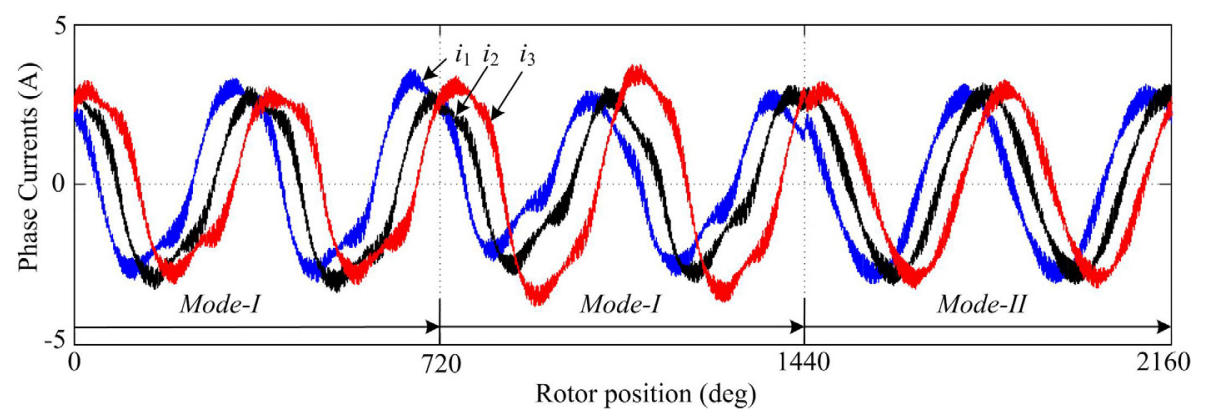

Figure 8. Phase currents in the imbalanced condition.

\subsection{Dynamic Response}

For a high performance drive system, the response to the speed control signal should be very fast, and its dynamic transition should be as smooth as possible. Figure 9 shows the phase current, speed and torque profiles of the NP-FSPM motor after the closed-loop speed operation is established. During the acceleration period, the motor generates near the maximum torque to accelerate the inertia up to the rated speed, taking $0.02 \mathrm{~s}$ from 0 to constant $300 \mathrm{rpm}$, and the controller adjusts the current magnitude to control the speed.

The investigations under different load step changes are carried out and the results are shown in Figure 10 (starts with $50 \mathrm{~N} \cdot \mathrm{m}$ at $0 \mathrm{~s}$, then changes to $100 \mathrm{~N} \cdot \mathrm{m}$ at $0.01 \mathrm{~s}$ ). Because of the decoupling feedback between the current control axes, $i_{\mathrm{d} 1}$ and $i_{\mathrm{q} 1}$ currents can in theory be controlled independently despite simultaneous change of both currents in the transient response, thus enabling fast current changes with negligible disturbance between axes. As seen from Figure 10b, the speed tracking is 
accurate but somewhat slow due to the large moment of inertia, with a transient response from $0.01 \mathrm{~s}$ to $0.012 \mathrm{~s}$. Nevertheless, the results demonstrate a good dynamic performance of the torque tracking.

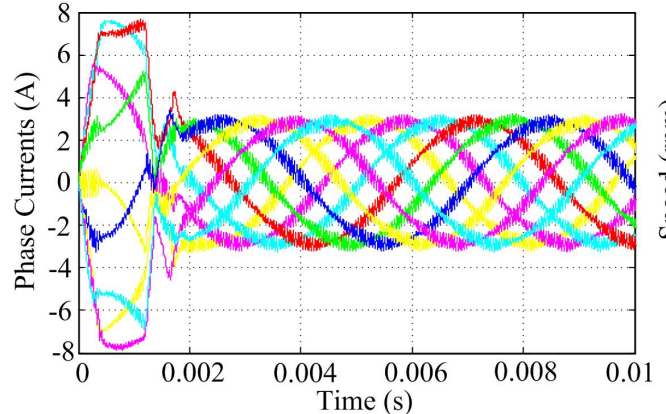

(a)

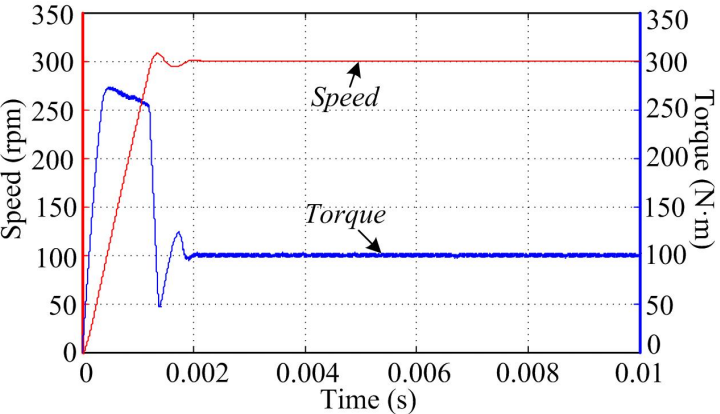

(b)

Figure 9. Simulation evaluation of start-up performance. (a) Phase currents response; (b) Speed and torque response.

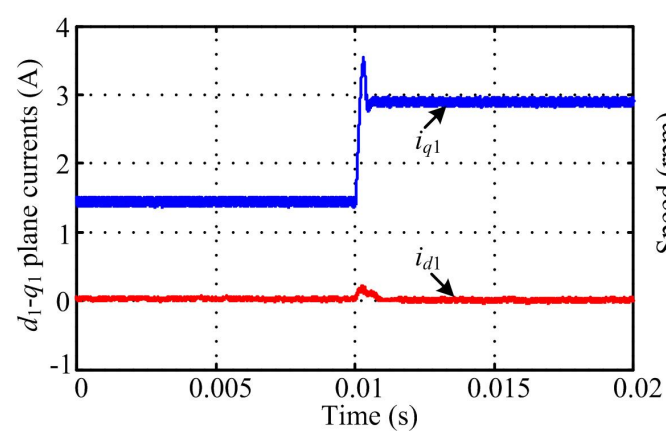

(a)

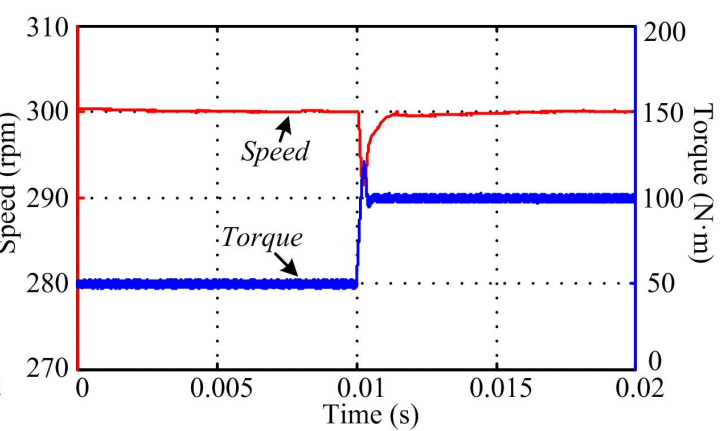

(b)

Figure 10. Simulation evaluation of load step change performance. (a) $d_{1-}-q_{1}$ plane currents response; (b) Speed and torque response.

\subsection{Post-Fault Operations}

When the open-circuit fault occurs in the phase 1 winding at $0.02 \mathrm{~s}$, the phase currents of the NP-FSPM motor become uncontrollable and a torque ripple of 15\% is apparent as shown in Figure 11a. The simulation results of post-fault operations with Minor, Mid, and MAX Reconstruction modes are shown in Figure 11b-d, respectively. It can be seen that all the three fault-tolerant modes are able to bring the system back to proper operation. The torque oscillations are efficiently reduced, and the system can be operated continuously and steadily after the open-circuit fault occurrence. Figure $11 \mathrm{~b}$ presents the phase currents and torque waveforms by reconstructing only the third harmonic current, the highest peak current value (of phase-4) is about $98 \%$ higher than the peak value under the normal condition. It must also be noted that the transient torque is relatively larger. While in the Mid Reconstruction mode as shown in Figure 11c, where both the fifth harmonic and seventh harmonic currents are simultaneously reconstructed, the highest peak value (of phase-6) becomes $41 \%$ higher. In the post-fault operation, the minimum peak phase current value can be achieved in Max Reconstruction mode, corresponding to a peak value of 3.8 A (phase-2), as shown in Figure 11d. Furthermore, negligible transient torque is exhibited in Figure 11c,d. 

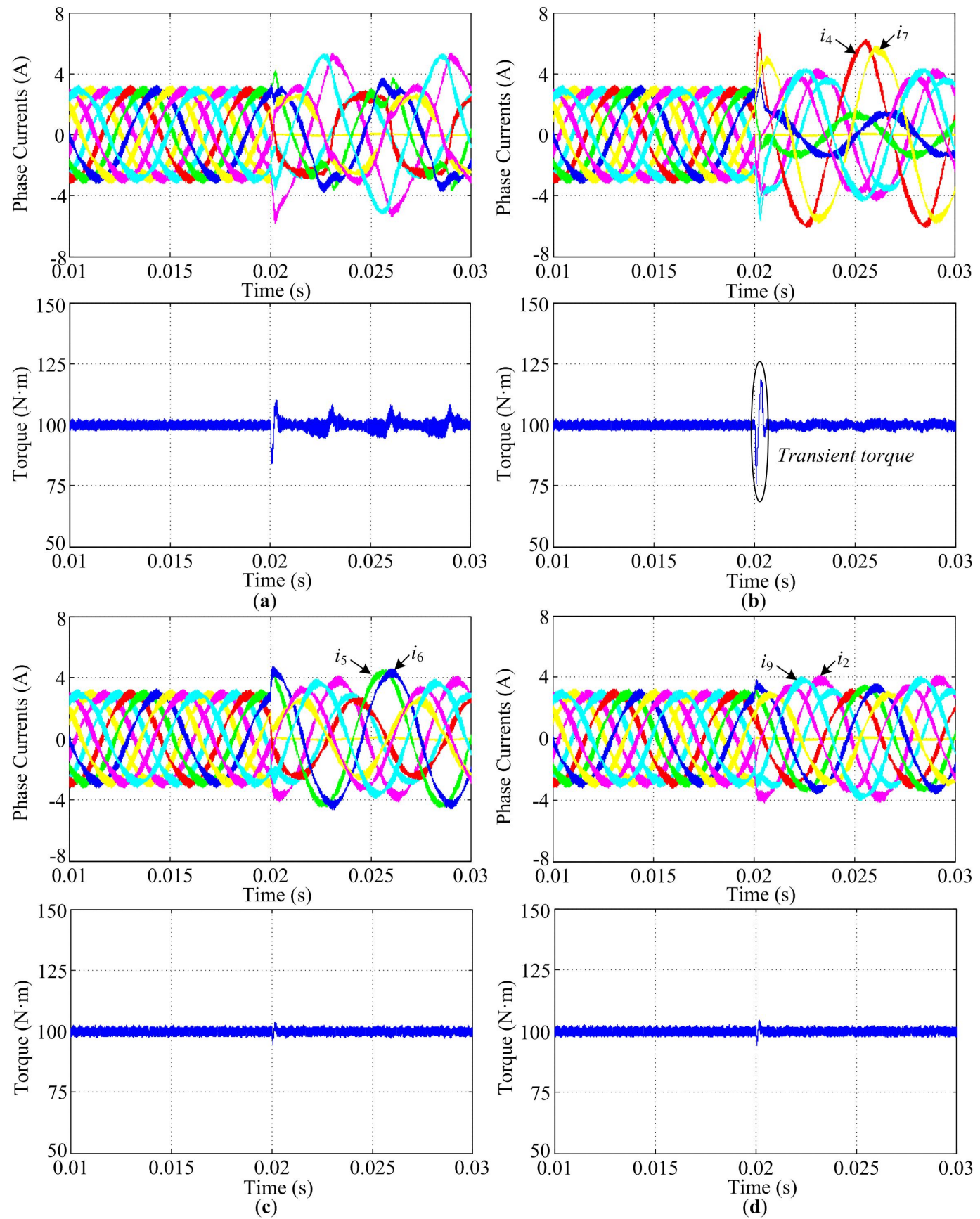

Figure 11. Simulation evaluation of post-fault operation. (a) Faulty operation; (b) Minor Reconstruction; (c) Mid Reconstruction; (d) Max Reconstruction.

\section{Experimental Validation}

Figure 12 shows a photograph of the experiment setup. A prototype of 36/34-pole NP-FSPM motor drive has been designed and built for verification. A custom-made nine-leg insulated gate bipolar transistor (IGBT) based inverter is used to supply the motor. A permanent magnet DC motor is mechanically coupled to the NP-FSPM motor as load. The complete control algorithm is implemented on a PC-based dSPACE1005 controller board. Motor phase currents are measured (using the LEM hall-effect current sensors) through dSPACE at a sampling frequency of $10 \mathrm{kHz}$. 


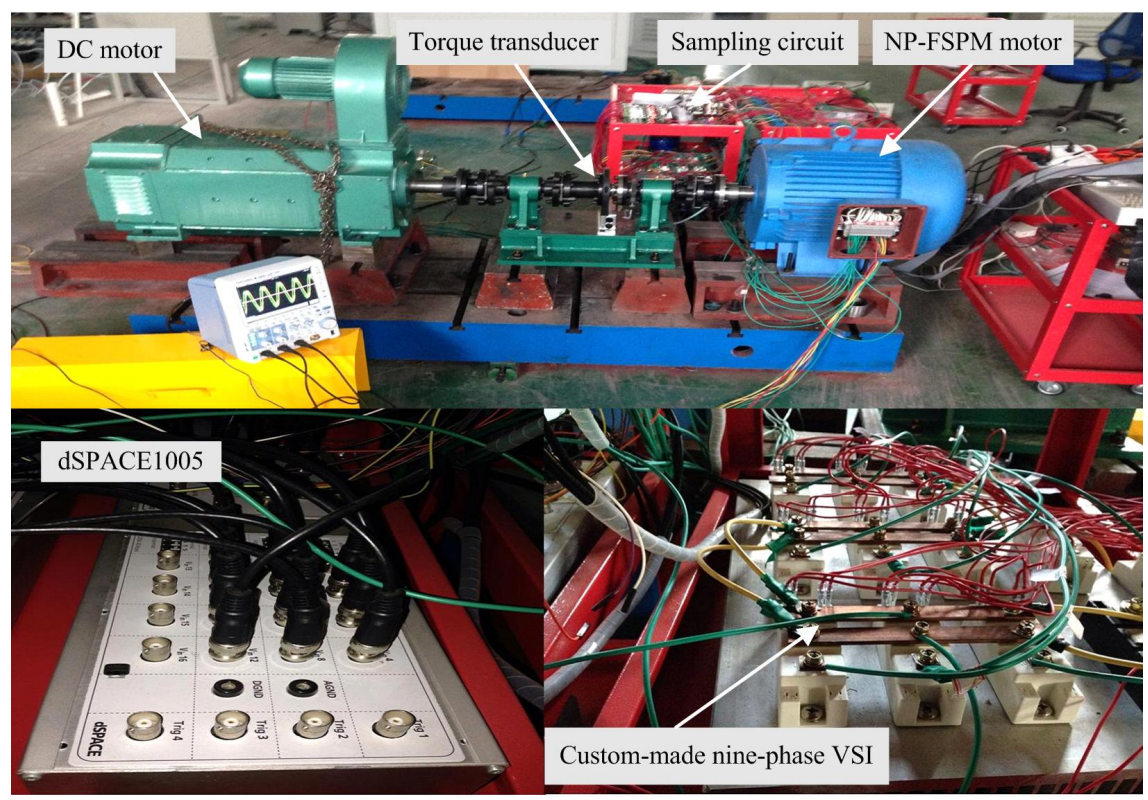

Figure 12. Experiment setup.

The steady-state performance of the fully-decoupled current control is presented in Figure 13. As seen in Figure 13a, the phase current waveforms are sinusoidal and phase-shifted by $2 \pi / 9$, which are in good agreement with the theoretical ones shown in Figure 7. In addition, the NP-FSPM motor operates steadily with low torque pulsation. Figure $13 \mathrm{~b}$ shows the synchronous current component traces in four pairs of synchronous frames. All the synchronous-frame current components are theoretically controlled at zero, accompanied with a constant value $(2.7 \mathrm{~A})$ of stator $q_{1}$-axis current, hence ensuring well-decoupled drive system.

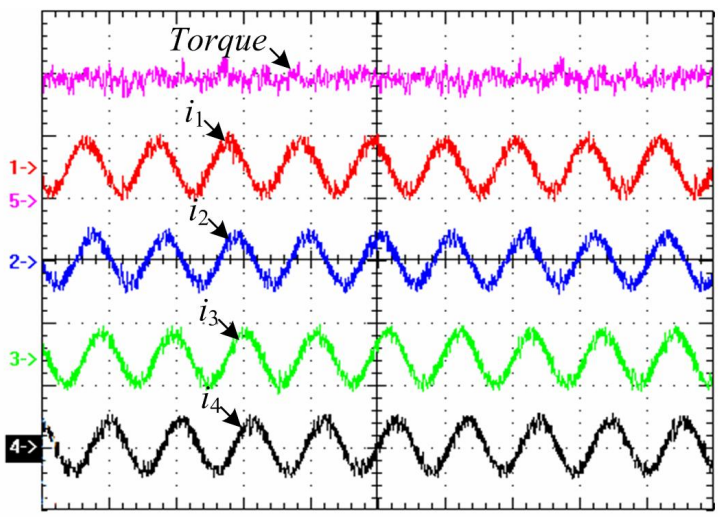

(a)

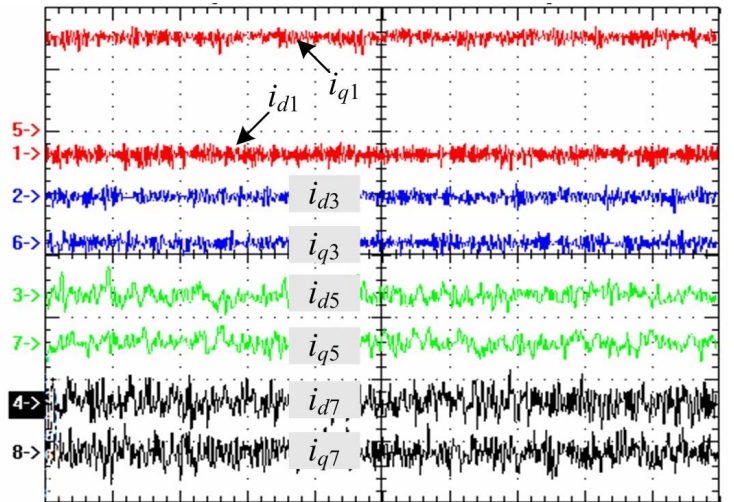

(b)

Figure 13. Experimental evaluation of steady-state performance with fully decoupled current control. (a) (Traces 1-4) Measured phase current waveforms, and (Trace 5) measured torque (6 ms/div, $5 \mathrm{~A} / \mathrm{div}, 50 \mathrm{~N} \cdot \mathrm{m} / \mathrm{div}$ ); (b) (Traces 1-8) Measured synchronous current components $(6 \mathrm{~ms} / \mathrm{div}, 2 \mathrm{~A} / \mathrm{div})$.

To test the dynamic performance of the closed-loop speed control, the machine starts with $50 \mathrm{~N} \cdot \mathrm{m}$ load and then changes to the condition of $100 \mathrm{~N} \cdot \mathrm{m}$ load at $300 \mathrm{rpm}$. The measured responses under sudden load step-change are shown in Figure 14, where the motor phase currents and torque follow the 
load torque rapidly; consequently, the motor speed returns to its reference value in a very short period, demonstrating that the current control provides fast and accurate control, independently of the operation mode of the machine.

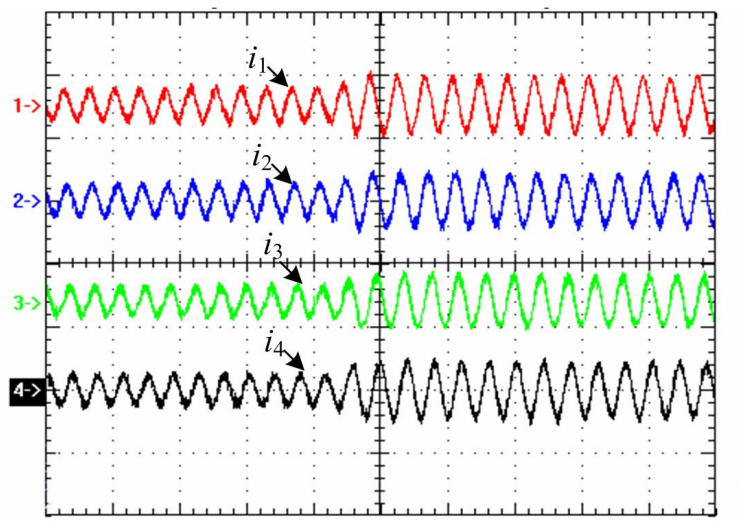

(a)

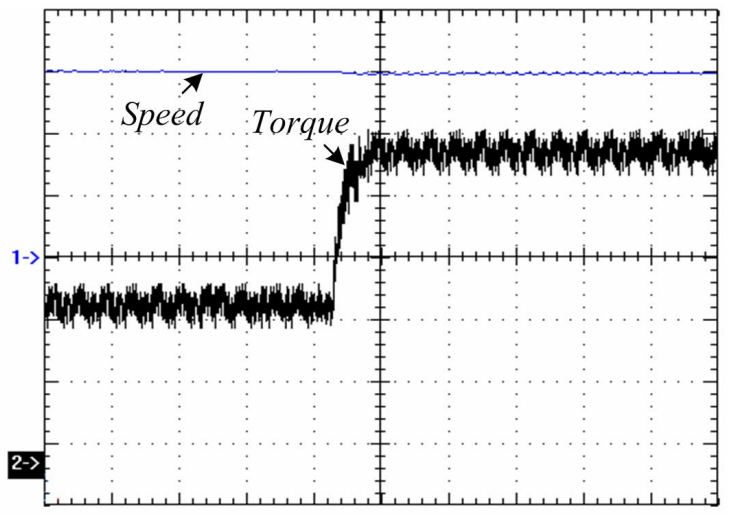

(b)

Figure 14. Experimental evaluation of load step-change performance. (a) (Traces 1-4) Measured phase current waveforms (15 ms/div, $5 \mathrm{~A} / \mathrm{div}$ ); (b) (Trace 1) Measured speed, and (Trace 2) measured torque (15 ms/div, $100 \mathrm{rpm} / \mathrm{div}, 20 \mathrm{~N} \cdot \mathrm{m} / \mathrm{div})$.

Figure 15 shows the start-up current, speed and torque responses, confirming that the machine drive offers good self-starting performance. It is worthy of mention that an instantaneous torque of up to $220 \mathrm{~N} \cdot \mathrm{m}$ can be achieved with an instantaneous peak value of phase current of only $6 \mathrm{~A}$.

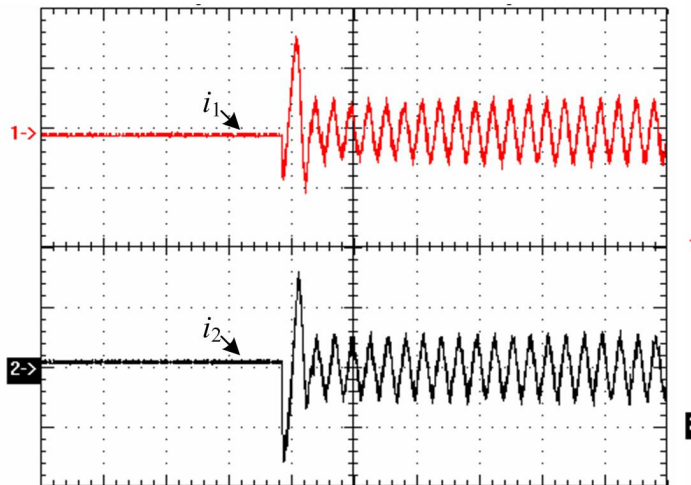

(a)

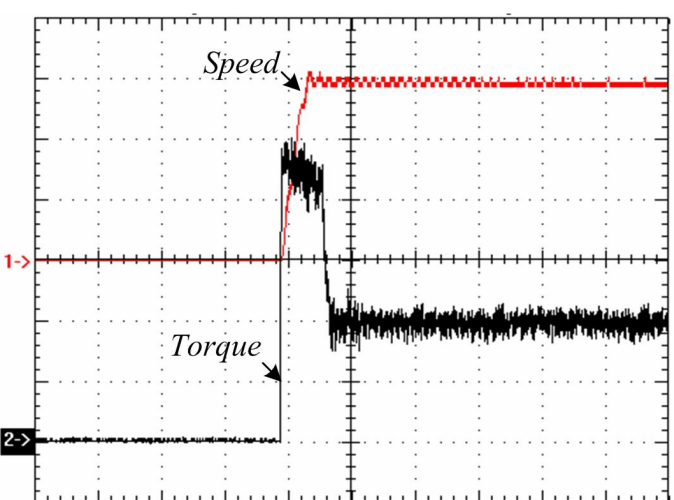

(b)

Figure 15. Experimental evaluation of start-up performance. (a) (Traces 1-2) Measured phase current waveforms (25 ms/div, $5 \mathrm{~A} / \mathrm{div})$; (b) (Trace 1) Measured speed, and (Trace 2) measured torque $(25 \mathrm{~ms} / \mathrm{div}, 100 \mathrm{rpm} / \mathrm{div}, 50 \mathrm{~N} \cdot \mathrm{m} / \mathrm{div})$.

In order to test the fault-tolerance of the NP-FSM motor drive system, an open-circuit fault was forced to occur in phase 1, and the post-fault operation of the NP-FSPM motor evaluated. Figure 16 shows the response of current and torque before and after the remedial Mid Reconstruction mode $\left(i_{\alpha 5}=i_{\alpha 7}=-i_{\alpha 1} / 2\right)$. As expected, these current waveforms agree well with the simulated results shown in Figure 11, with negligible torque pulsation during this transient, confirming that the machine drive can achieve disturbance-free operation under fault conditions. 


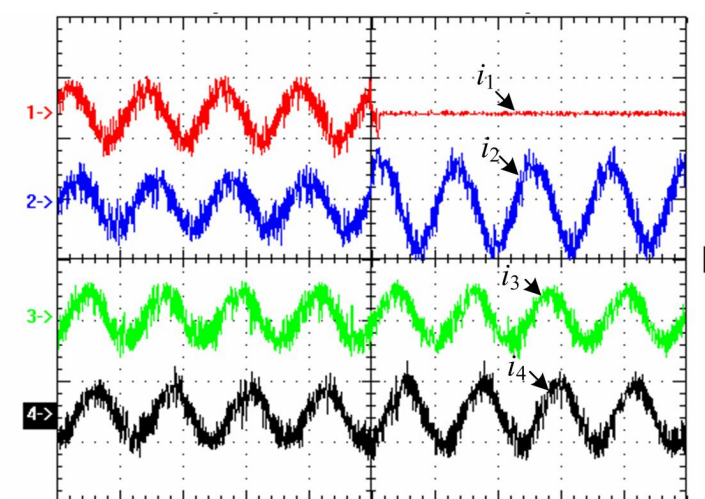

(a)

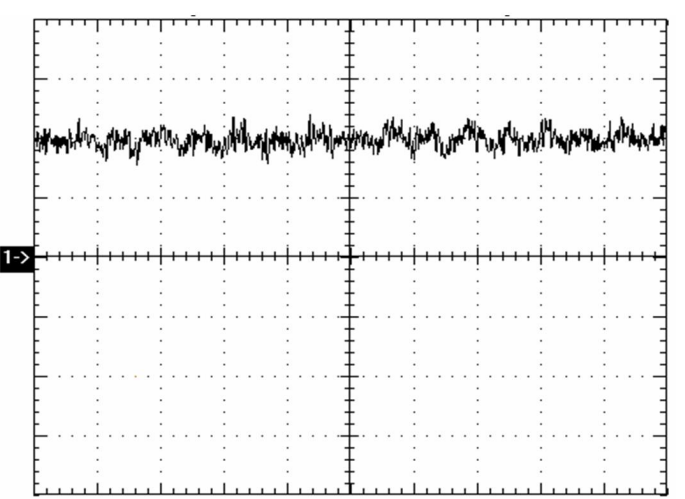

(b)

Figure 16. Experimental evaluation of post-fault operation performance. (a) (Traces 1-4) Measured phase current waveforms ( $5 \mathrm{~ms} / \mathrm{div}, 5 \mathrm{~A} / \mathrm{div}$ ); (b) Measured torque ( $5 \mathrm{~ms} / \mathrm{div}$, $50 \mathrm{~N} \cdot \mathrm{m} / \mathrm{div})$.

\section{Conclusions}

FSPM motors with a higher number of phases offer better static torque capability with lower torque ripple in steady-state operation as compared to conventional three-phase configurations. This paper has investigated potential complexities in the dynamic control and reliability enhancement of a 36/34-pole NP-FSPM motor for use in an HEV. For this purpose, a fully decoupled current control system is designed based on vector space decomposition. Possibilities for the implementation of a fault-tolerant operating strategy are further elaborated. Both simulation and experiments were conducted to verify that the drive system and its controller are effective and reliable in ensuring the desired operation of an HEV in the low-speed region.

\section{Acknowledgments}

This work was supported by the National Key Basic Research Program (973 Program) of China under Project 2013CB035603.

\section{Author Contributions}

Ming Cheng and Kwok Tong Chau provided guidance and supervision; Feng Li performed the Finite-element analysis; Feng $\mathrm{Yu}$ implemented the research, performed the simulation and experimental analysis and wrote the paper. All authors have contributed significantly to this work.

\section{Conflicts of Interest}

The authors declare no conflict of interest.

\section{References}

1. Emadi, A.; Lee, Y.J.; Rajashekara, K. Power electronics and motor drives in electric, hybrid electric, and plug-in hybrid electric vehicles. IEEE Trans. Ind. Electron. 2008, 6, 2237-2245. 
2. Cheng, M.; Chan, C.C. General requirement of traction motor drives. In Encyclopedia of Automotive Engineering; John Wiley \& Sons Ltd: Chichester, UK, 2015; Volume 3, pp. 1261-1278.

3. Chau, K.T.; Chan, C.C.; Liu, C.H. Overview of permanent-magnet brushless drives for electric and hybrid electric vehicles. IEEE Trans. Ind. Electron. 2008, 6, 2246-2257.

4. Cheng, M.; Sun, L.; Buja, G.; Song, L. Advanced electrical machines and machine-based systems for electric and hybrid vehicles. Energies 2015, 8, 9541-9564.

5. Amara, Y.; Vido, L.; Gabsi, M.; Hoang, E.; Ben, A.H.; Lecrivain, M. Hybrid excitation synchronous machines: Energy-efficiency solution for vehicles propulsion. IEEE Trans. Veh. Technol. 2009, 5, 2137-2149.

6. Cheng, M.; Hua, W.; Zhang, J.; Zhao, W. Overview of stator-permanent magnet brushless machine. IEEE Trans. Ind. Electron. 2011, 11, 5087-5101.

7. Cao, R.; Mi, C.; Cheng, M. Quantitative comparison of flux-switching permanent-magnet motors with interior permanent magnet motor for EV, HEV, and PHEV applications. IEEE Trans. Magn. 2012, 8, 2374-2384.

8. Li, F.; Hua, W.; Tong, M.; Zhang, G.; Cheng, M. Nine-phase flux-switching permanent magnet brushless machine for low-speed and high-torque applications. IEEE Trans. Magn. 2014, 51, 1-4.

9. Li, F.; Hua, W.; Cheng, M.; Zhang, G. Analysis of fault tolerant control for a nine-phase flux-switching permanent machine. IEEE Trans. Magn. 2014, 50, 1-4.

10. Zhao, W.; Cheng, M.; Chau, K.T.; Cao, R.; Ji, J. Remedial injected-harmonic-current operation of redundant flux-switching permanent-magnet motor drives. IEEE Trans. Ind. Electron. 2013, 1, 151-159.

11. Thomas, A.S.; Zhu, Z.Q.; Owen, G.W.; Howe, D. Multiphase flux-switching permanent-magnet brushless machine for aerospace application. IEEE Trans. Ind. Appl. 2009, 6, 1971-1981.

12. Xue, X.; Zhao, W.; Zhu, J.; Liu, G.; Zhu, X.; Cheng, M. Design of five-phase modular flux-switching permanent-magnet machines for high reliability applications. IEEE Trans. Magn. 2013, 7, 3941-3944.

13. Yu, F.; Cheng, M.; Hua, W.; Chau, K.T. Fault tolerant control of triple star-winding flux-switching permanent magnet motor drive due to open phase. In Proceedings of the Tenth International Conference on Ecological Vehicles and Renewable Energies, Monte-Carlo, Monaco, 31 March-2 April 2015; pp. 1-9.

14. Zhao, W.; Cheng, M.; Chau, K.T.; Hua, W. Stator-flux-oriented fault-tolerant control of flux-switching permanent-magnet motors. IEEE Trans. Magn. 2011, 10, 4191-4194.

15. Yu, F.; Cheng, M.; Li, F.; Chau, K.T.; Huang, J. Fault tolerant control of harmonic injected nine-phase flux switching permanent magnet motor drive system. In Proceedings of the 17th International Conference on Electrical Machines and Systems, Hangzhou, China, 22-25 October 2014; pp. 3117-3122.

16. Jones, M.; Vukosavic, S.N.; Dujic, D.; Levi, E. A synchronous current control scheme for multiphase induction motor drives. IEEE Trans. Energy Convers. 2009, 4, 860-868.

17. Che, H.S.; Levi, E.; Jones, M.; Hew, W.P. Current control methods for an asymmetrical six-phase induction motor drive. IEEE Trans. Power Electron. 2014, 1, 407-416. 
18. Karttunen, J.; Kallio, S.; Peltoniemi, P.; Silventoinen, P. Decoupled vector control scheme for dual three-phase permanent magnet synchronous machines. IEEE Trans. Ind. Electron. 2014, 5, 2185-2196.

19. Cao, R.; Cheng, M.; Zhang, B. Speed control of complementary and modular linear flux-switching permanent-magnet motor. IEEE Trans. Ind. Electron. 2015, 7, 4056-4064.

20. Parsa, L.; Toliyat, H.A. Fault-tolerant interior-permanent-magnet machines for hybrid electric vehicle applications. IEEE Trans. Veh. Technol. 2007, 4, 1546-1552.

21. Tani A.; Mengoni, M.; Zarri, L.; Serra, G.; Casade, D. Control of multiphase induction motors with an odd number of phases under open-circuit phase faults. IEEE Trans. Power Electron. 2012, 2, 565-577.

22. Che, H.S.; Duran, M.J.; Levi, E.; Jones, M. Post-fault operation of an asymmetrical six-phase induction machine with single and two isolated neutral points. IEEE Trans. Power Electron. 2014, 10, 2406-2416.

23. Guzman, H.; Duran, M.J.; Barrero, F.; Bogado, B.; Toral, S. Speed control of five-phase induction motors with integrated open-phase fault operation using model-based predictive current control techniques. IEEE Trans. Ind. Electron. 2014, 9, 4474-4484.

24. Karugaba, S.; Ojo, O. A carrier-based PWM modulation technique for balanced and unbalanced reference voltages in multiphase voltage-source inverters. IEEE Trans. Ind. Appl. 2012, 6, 2102-2109.

(C) 2015 by the authors; licensee MDPI, Basel, Switzerland. This article is an open access article distributed under the terms and conditions of the Creative Commons Attribution license (http://creativecommons.org/licenses/by/4.0/). 